Portland State University

PDXScholar

Physics Faculty Publications and Presentations

Physics

$10-11-2011$

\title{
Frequency multiplication in nanowires
}

\author{
Marius Ghita \\ Portland State University \\ Ed Godshalk \\ Portland State University \\ Gary Goncher \\ Portland State University \\ Raj Solanki \\ Portland State University
}

Follow this and additional works at: https://pdxscholar.library.pdx.edu/phy_fac

Part of the Physics Commons

Let us know how access to this document benefits you.

\section{Citation Details}

Ghita, M., Godshalk, E., Goncher, G., \& Solanki, R. (2011). Frequency multiplication in nanowires. [Article]. Applied Physics Letters, 99(15), 3.

This Article is brought to you for free and open access. It has been accepted for inclusion in Physics Faculty Publications and Presentations by an authorized administrator of PDXScholar. Please contact us if we can make this document more accessible: pdxscholar@pdx.edu. 


\title{
Frequency multiplication in nanowires
}

\author{
Marius Ghita, ${ }^{1}$ Ed Godshalk, ${ }^{1,2}$ Gary Goncher, ${ }^{1, a)}$ and Raj Solanki ${ }^{1}$ \\ ${ }^{1}$ Department of Physics, Portland State University, Portland, Oregon 97007, USA \\ ${ }^{2}$ Maxim Integrated Products, Beaverton, Oregon 97005, USA
}

(Received 12 August 2011; accepted 12 September 2011; published online 11 October 2011)

\begin{abstract}
Frequency multiplication in silicon and $\mathrm{ZnO}$ nanowire based Schottky and $\mathrm{p}-\mathrm{n}$ diodes has been demonstrated at fundamental frequencies of $70 \mathrm{MHz}$ and $500 \mathrm{MHz}$. Our motivation for using nanowires contacted at their tips was to minimize the spreading resistance and boundary capacitance in order to produce higher cut-off frequencies and conversion efficiencies compared to planar diodes. The data presented here are limited to the lower $\mathrm{GHz}$ range by the frequency response of the experimental apparatus. However, by employing microwave waveguides and higher fundamental source frequencies, it should be possible to reach much higher output frequencies with nanowire-based diodes. (C) 2011 American Institute of Physics. [doi:10.1063/1.3646913]
\end{abstract}

Frequency multiplication is a useful technique for extending the range of signal generators for high frequency communications and sensing technologies. Generation of $\mathrm{mm}$ wave radiation in particular is practical principally because of efficient frequency multipliers, ${ }^{1}$ and the technique has been extensively investigated for producing solid state THz sources. ${ }^{2-5}$ Frequency multiplication is dependent upon electrical elements with nonlinear characteristics; both diodes and transistors have been used for this application, as well as some ambipolar devices. The most practical devices to date for producing very high frequencies have been GaAs Schottky diodes, due to their high mobilities and relatively low parasitics when fabricated with extremely small dimensions using state of the art fabrication technologies. ${ }^{4}$ However, output power is limited in these devices.

In order to reduce parasitics that limit high frequency operation of devices, several nanomaterials have been investigated. The nonlinear characteristics of transistors fabricated from very highly conducting graphene material have recently been shown to generate harmonic radiation. ${ }^{6}$ Carbon nanotubes have also been used to generate harmonic radiation using ultrashort optical pulses. ${ }^{7-9}$ Carbon nanotube Schottky diodes have been fabricated as high frequency sensors with diode characteristics. ${ }^{10} \mathrm{ZnO}$ semiconductor nanowires have also been used to produce second harmonics using femtosecond laser excitation. ${ }^{11}$ In this work, we have investigated harmonic generation using $\mathrm{CW}$ radiation in diodes fabricated from silicon and $\mathrm{ZnO}$ nanowires.

For frequency multiplication in diodes, the nonlinear characteristics of diodes are used. The diode current $\left(\mathrm{I}_{\mathrm{D}}\right)$ can be expressed as

$$
I_{D}=I_{0}\left(e^{\frac{V}{V_{t h}}}-1\right)=I_{0}\left(\frac{V}{V_{t h}}+\frac{1}{2}\left(\frac{V}{V_{t h}}\right)^{2}+\frac{1}{6}\left(\frac{V}{V_{t h}}\right)^{3}+\ldots\right),
$$

where $\mathrm{V}_{\text {th }}=\mathrm{kT} / \mathrm{q} \approx 0.026 \mathrm{~V}$ at room temperature, and a Taylor series expansion of the exponential is used. By substi-

\footnotetext{
a) Author to whom correspondence should be addressed. Electronic mail: ggoncher@frontier.com.
}

tuting $\mathrm{V}=\mathrm{V}_{0} \cos (\omega \cdot \mathrm{t})$ in this equation and using trigonometric identities for cosine terms, the diode current becomes

$$
I_{D} \approx I_{d c}+I_{1} \cos (\omega t)+I_{2} \cos (2 \omega t)+I_{3} \cos (3 \omega t)+\ldots
$$

Equation (2) shows that the output of a non-linear system characterized by Eq. (1) and stimulated by a sinusoidal input will contain harmonics of the input signal. This is the basic principle that is employed by frequency multipliers which exploit the non-linearity of the I-V characteristics of a diode. Moreover, in the traditional high-frequency model of a Schottky diode, a useful figure of merit is the cut-off frequency that is expressed as $f_{c}=1 / 2 \pi r_{c} C_{b}$, where $r_{c}$ is the spreading resistance and $\mathrm{C}_{\mathrm{b}}$ is the barrier capacitance. ${ }^{12}$ Of these two parameters, the spreading resistance is very critical since it drastically affects the conversion efficiencies of any diode harmonic generator. The device dissipates power not only at the input and output harmonic frequencies, but also at every idler frequency for which the current may flow through it. ${ }^{13}$ Both of these parameters can be minimized by employing a semiconductor in the form of a nanowire and contacting it at its tip. By reducing the metal/semiconductor contact area, it can be seen from the above expression that

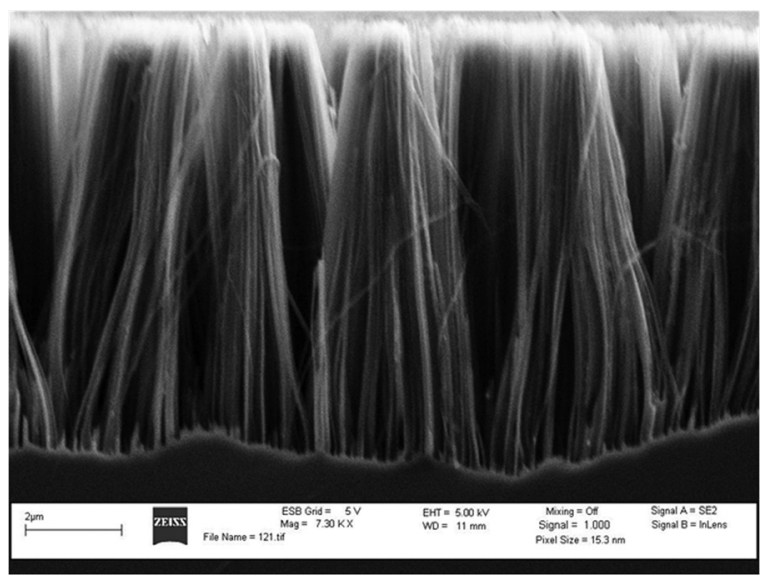

FIG. 1. Scanning electron microscope side view of an etched silicon nanowire sample. Clumping of nanowires near the tips can be observed at the top of the image. 


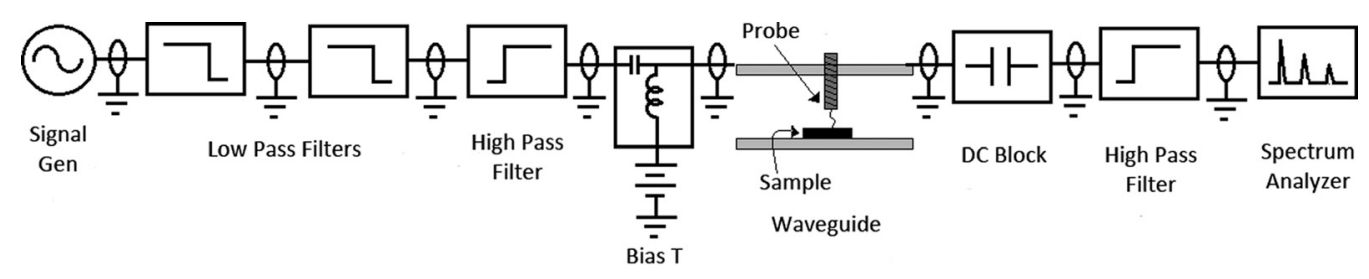

FIG. 2. Microstrip harmonic measurement setup.

besides improving the conversion efficiency, the harmonic frequency of such diodes will also be extended. ${ }^{14}$ We have considered these factors and examined frequency multiplication from nanowire based diodes at source frequencies of $70 \mathrm{MHz}$ and $500 \mathrm{MHz}$ to demonstrate the proof of concept for multiplication in this type of devices.

Silicon nanowires (SiNWs) for this investigation were synthesized using an aqueous electroless etching method. ${ }^{15}$ The mechanism is based on electroless metal (silver) deposition in an hydrofluoric acid (HF) solution where both anodic and cathodic processes occur simultaneously. ${ }^{16}$ Cleaned silicon wafer pieces were etched for $60 \mathrm{~min}$ in a 5 molar HF solution containing 0.02 molar silver nitrate at $50{ }^{\circ} \mathrm{C}$. After the etch, the substrates were rinsed in deionized water and then soaked in nitric acid to for about $5 \mathrm{~min}$ to remove a loosely bonded residual silver film. The length of these SiNWs can be controlled by adjusting the etch time. Two types of nanowires were prepared: N-type (1-10 $\Omega$-cm) for Schottky diodes and NWs with $\mathrm{N}^{+}\left(0.340 \Omega\right.$-cm) $/ \mathrm{P}^{+}(0.01-0.02 \Omega$-cm) junctions for $\mathrm{p}-\mathrm{n}$ diodes. The $\mathrm{p}-\mathrm{n}$ diodes were fabricated by first growing a $\mathrm{N}^{+}$epitaxial layer on a $\mathrm{P}^{+}$wafer and then etching nanowires on these substrates. The nanowires had diameters of about $180 \mathrm{~nm}$ and heights of $6-10 \mu \mathrm{m}$. A side view of a typical nanowire samples is shown in Fig. 1 where the unconstrained ends of the nanowires exhibited some clumping, probably due to surface tension during the drying process after fabrication. $\mathrm{Al}$ doped $\mathrm{ZnO}$ (N-type) nanowire Schottky diodes were also tested for harmonics. These NWs were produced by an electrodeposition process, followed by annealing. ${ }^{17}$

Initially, current-voltage characteristics were measured for the nanowire samples by contacting the surface with a tungsten whisker probe with a tip diameter of approximately $0.35 \mu \mathrm{m}$. The tungsten probe was assumed to make an ohmic contact to the $\mathrm{N}^{+}$tip of the junction diode and a Schottky contact to the N-type nanowires. Nanowire samples were measured for harmonic generation in an air microstrip apparatus (Figure 2). The etched silicon nanowire substrates were cleaved into about $1.5 \mathrm{~mm} \times 1 \mathrm{~mm}$ pieces and then placed on a brass carrier that was mounted between a signal line and ground plane. The tungsten probe was mounted at the end of a screw that allowed the wire to slowly be brought into contact with the top surface of the nanowires until current was observed. Considering the tip area of the tungsten probe and the density of silicon nanowires, it is safe to assume that the probe is contacting tens of nanowire diodes. The microstrip set-up consisted of a sine wave generator set at fundamental frequencies of 70 or $500 \mathrm{MHz}$, and the harmonic output was measured on a Tektronix 494P spectrum analyzer. Two band pass filters attenuated unwanted harmonics inherent in the signal source. A low pass filter provided additional sup- pression of spurious harmonics. A high pass filter at the input to the spectrum analyzer reduced harmonic generation in its front-end mixer. Placing a bias tee and dc block on either side of the device under test (DUT), blocked dc current flow to the $50-\Omega$ loads presented by both the signal generator and spectrum analyzer and allowed the DUT to be biased.

The microstrip multiplier was first tested with a commercial, high-speed Schottky diode (Metellics P/N CDLL2810), and $70 \mathrm{MHz}$ harmonics were easily measured to beyond $1 \mathrm{GHz}$ which confirmed the functionality of the multiplier system. Conversion gain of the microstrip multiplier with no sample was then recorded at $70 \mathrm{MHz}$ with a power of +10 $\mathrm{dBm}$ to calibrate out any spurious signals. The nanowire samples were next tested with the tungsten whisker. Results for harmonic generation using nanowire samples are shown in Figure 3. Two types of silicon nanowire diodes are shown in the figure: a $\mathrm{p}+\mathrm{n}+$ diode and an n-type nanowire Schottky diode. To show that this process is not limited to silicon, harmonics from an n-type $\mathrm{ZnO}$ nanowire Schottky diode is also included. The same procedure was repeated with a drive signal of $500 \mathrm{MHz}$, with appropriate filters. At this frequency, harmonics from both types of $\mathrm{Si}$ diodes and the commercial diode were observed only at $1 \mathrm{GHz}$ and $1.5 \mathrm{GHz}$. Our analysis shows that the upper limit of the harmonics is limited by our microstrip set-up. In order to generate higher frequency harmonics, a higher frequency waveguide is required.

In summary, we have demonstrated frequency multiplication in silicon nanowire Schottky and p-n diodes and a $\mathrm{ZnO}$ nanowire Schottky diode. Although the technique used here to contact the nanowires is crude, it has allowed us to demonstrate proof of concept for frequency multiplication in these materials. Ideally, each of these devices should consist

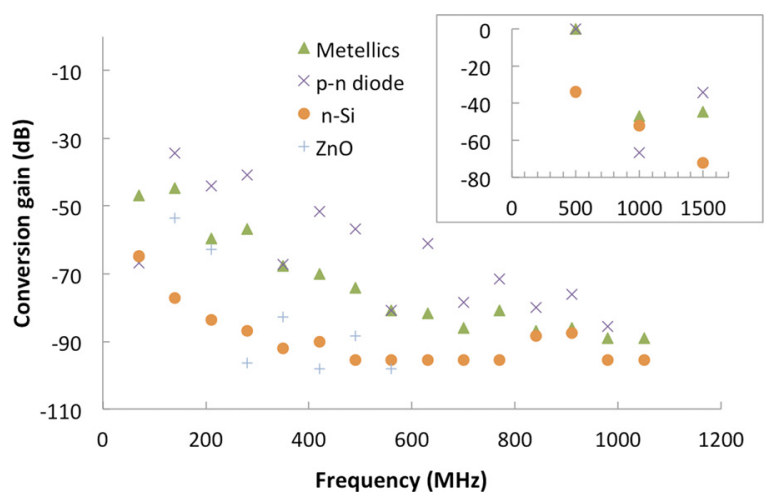

FIG. 3. (Color online) Harmonic generation from p-n and Schottky silicon nanowire diodes and $\mathrm{ZnO}$ Schottky nanowire diode in the microstrip multiplier for a $70 \mathrm{MHz}$ fundamental frequency. The inset shows the harmonics for a $500 \mathrm{MHz}$ fundamental frequency. Harmonic output of a commercial high speed Schottky diode (Metellics CDLL2810) is shown for comparison. 
of a single nanowire fused to a metal probe to form a Schottky contact, however, achieving such a contact is a considerable technical challenge and is one of the objectives of our future work. The small contact area of the semiconductor nanowires as substrates for these diodes minimizes the spreading resistance and the boundary capacitance resulting in high cut-off frequencies and conversion efficiencies. This approach should work with other nanostructures such as semiconducting carbon nanotubes. The harmonics obtained with the current measurement method are limited by our microstrip set-up. Future work is planned using nanowire samples mounted in a stepped microwave waveguide using input frequencies $>50 \mathrm{GHz}$, since, in principle, there is no reason that frequency generation from nanowires cannot be extended to the $\mathrm{THz}$ region.

The authors wish to thank Professor Rolf Konenkamp for providing $\mathrm{ZnO}$ nanowires. This work was funded by the Army Research Laboratory through Oregon Nanoscience and Microtechnologies Institute.

${ }^{1}$ J. T. Louhi and A. V. Raisanen, IEEE Microw. Guid. Wave Lett. 6, 241 (1996).

${ }^{2}$ A. Maestrini, J. Ward, J. Gill, H. Javadi, E. Schlecht, G. Chattopadhyay, F. Maiwald, N. R. Erickson, and I. Mehdi, IEEE Microw. Wirel. Compon. Lett. 14, 253 (2004).
${ }^{3}$ J. Ward, E. Schlect, G. Chattopadhyay, A. Maestrini, J. Gill, F. Maiwald, H. Javadi, and I. Mehdi, IEEE MTT-S Int. Microwave Symp. Dig. 2004, 1587.

${ }^{4}$ I. Mehdi, G. Chattopadhyay, E. Schlecht, J. Ward, J. Gill, F. Maiwald, and A. Maestrini, IEEE MTT-S Int. Microwave Symp. Dig. 2006, 341.

${ }^{5}$ G. Chattopadhyay, E. Schlect, J. S. Ward, J. J. Gill, H. H. S. Javadi, F. Maiwald, and I. Mehdi, IEEE Trans. Microwave Theory Tech. 52, 1538 (2004).

${ }^{6}$ H. Wang, D. Nezich, J. Kong, and T. Palacios, IEEE Electron Device Lett. 30, 547 (2009).

${ }^{7}$ G. Y. Slepyan, S. A. Maksimenko, V. P. Kalosha, J. Hermann, E. E. B. Campbell, and I. V. Hertel, Phys. Rev. A 60, R777 (1999).

${ }^{8}$ G. Y. Slepyan, S. A. Maksimenko, V. P. Kalosha, A. V. Gusakov, and J. Hermann, Phys. Rev. A 63, 053808 (2001).

${ }^{9}$ C. Stanciu, R. Ehlich, V. Petrov, O. Steinkellner, J. Hermann, I. V. Hertel, G. Y. Slepyan, A. A. Khrutchinski, S. A. Maksimenko, F. Rotermund, E. E. B. Campbell, and F. Rohmund, Appl. Phys. Lett. 81, 4064 (2002).

${ }^{10}$ H. M. Manohara, E. W. Wong, E. Schlect, B. D. Hunt, and P. H. Siegel, Nano Lett. 5, 1469 (2005).

${ }^{11}$ C. F. Zhang, Z. W. Dong, G. J. You, R. Y. Zhu, S. X. Qian, H. Deng, H. Cheng, and J. C. Wang, Appl. Phys. Lett. 89, 042117 (2006).

${ }^{12}$ K. S. Chamlin and G. Eisenstein, IEEE Trans. Microwave Theory Tech. MTT-26, 31 (1978).

${ }^{13}$ M. McColl, IEEE Trans. Microwave Theory Tech. MTT-25, 54 (1977).

${ }^{14}$ L. E. Dickens, IEEE Trans. Microwave Theory Tech. MTT-15, 101 (1967).

${ }^{15}$ K. Peng, Y. Yan, S. Gao, and J. Zhu, Adv. Funct. Mater. 13, 127 (2003).

${ }^{16}$ P. G. Stiza, M. A. Kulandainathan, R. Diaz, F. Sanz, P. Allongue, and J. R. Morante, J. Electrochem. Soc. 147, 1026 (2000).

${ }^{17}$ L. Dloczik, R. Engelhardt, K. Ernst, M. C. Lux-Steiner, and R. Könenkamp, Sensors Actuators B 84, 33 (2000). 